www.nature.com/pj

\title{
Polysaccharide nanogel-cyclodextrin system as an artificial chaperone for in vitro protein synthesis of green fluorescent protein
}

\author{
Yoshihiro Sasaki $^{1,2}$, Yuta Nomura ${ }^{1}$, Shin-ichi Sawada ${ }^{1}$ and Kazunari Akiyoshi ${ }^{1,3}$ \\ Polysaccharide nanogels have been demonstrated to aid the refolding processes of chemically or thermally denatured proteins, \\ a function that is similar to that of natural molecular chaperones. In this study, we examined the possibilities of using the \\ nanogel chaperone system to mediate protein folding in a cell-free (in vitro) protein synthesis system containing transcription/ \\ translation factors. High-performance liquid chromatography showed that a polysaccharide nanogel comprising cholesteryl \\ group-bearing pullulan (CHP) trapped unfolded or partially folded green fluorescent protein (GFP) expressed in the cell-free \\ system. The protein release and refolding processes, which are induced by ATP in natural molecular chaperone systems, were \\ also simulated by methyl- $\beta$-cyclodextrin (M- $\beta$-CD). The CHP nanogels dissociate on complexation with M- $\beta$-CD to yield \\ dissociated CHP. Thus, the dissociation of the CHP nanogel-protein complex subsequently allows for the release and folding \\ of GFP. The folding kinetics in the presence of the CHP nanogel and M- $\beta$-CD was comparable to that of spontaneous folding in \\ the absence of CHP/M- $\beta$-CD, indicating that the CHP nanogels did not affect protein synthesis in the cell-free system, providing \\ correctly folded active proteins.
}

Polymer Journal (2010) 42, 823-828; doi:10.1038/pj.2010.73; published online 18 August 2010

Keywords: cell-free protein synthesis; cyclodextrin; green fluorescent protein; molecular chaperone; polysaccharide nanogel

\section{INTRODUCTION}

The folding of proteins synthesized in vivo or in vitro has attracted considerable attention. ${ }^{1-3}$ Problems related to protein folding, including protein aggregation and misfolding, are involved in diseases such as Alzheimer's, Parkinson's and Huntington's, as well as in prion diseases. ${ }^{4-7}$ Moreover, the efficient production of a large amount of protein is a major focus of biotechnology and postgenome research fields. However, the folding of proteins synthesized in vitro into the correct active structure has proven to be difficult, because partially folded intermediate proteins are considerably hydrophobic and form aggregation and inclusion bodies. In biological systems, molecular chaperones such as GroEL/ES interact with unfolded nascent proteins and increase the efficiency of correct protein folding. ${ }^{8-12}$ Many artificial molecular chaperones have been developed, such as PEG, L-arginine, cyclodextrin derivatives, micelles and other polymers, to prevent protein aggregation and assist in the refolding of proteins synthesized in vitro. ${ }^{13-19}$

We have already reported that polysaccharide nanogels can function as artificial molecular chaperones. ${ }^{20}$ For example, nanogels formed with cholesteryl group-bearing pullulan (CHP) can trap heatdenatured proteins ${ }^{21}$ or chemically denatured proteins (that is, protein-refolding intermediates formed after chemical denaturation by urea or guanidinium hydrochloride) ${ }^{22,23}$ The CHP nanogel consists of stable monodisperse nanoparticles $(\sim 30 \mathrm{~nm})$ with $\sim 4-5 \mathrm{CHP}$ polymers per nanogel and approximately eight non-covalent crosslinking regions that consist of cholesteryl groups. ${ }^{24-26}$ The structure of the CHP nanogel is disrupted by the addition of cyclodextrins and the protein complexed with the nanogel is released and folds into its mature form, so that the CHP nanogels and cyclodextrins together function as an artificial chaperone. ${ }^{21}$ In a direct comparison of artificial and natural chaperone activity, the CHP nanogel system showed a high level of chaperone-like activity that was comparable to that of a natural molecular chaperone (GroEL/ES) system in the refolding of acid-denatured green fluorescent protein (GFP). ${ }^{27}$ This nanogel system was also effective for refolding the inclusion body of a recombinant protein belonging to the serine protease family. ${ }^{22}$ Moreover, the CHP nanogels interact with monomers and oligomers of amyloid $\beta$-protein $(\mathrm{A} \beta),{ }^{28}$ and the resulting complexes significantly reduce $A \beta$ toxicity in primary cortical cultures and in microglial cell cultures. ${ }^{29}$

The polysaccharide nanogel has been demonstrated to function as a chaperone in the refolding processes of various proteins. However, it is

${ }^{1}$ Institute of Biomaterials and Bioengineering, Tokyo Medical and Dental University, Tokyo, Japan; ${ }^{2}$ PRESTO, Japan Science and Technology Agency, Saitama, Japan and ${ }^{3}$ Global Center of Excellence Program, International Research Center for Molecular Science in Tooth and Bone Diseases, Tokyo Medical and Dental University, Tokyo, Japan Correspondence: Professor K Akiyoshi, Institute of Biomaterials and Bioengineering, Tokyo Medical and Dental University, 2-3-10 Kanda-Surugadai, Chiyoda, Tokyo 101-0062, Japan. 
still challenging to use the nanogel chaperone system to assist in the protein-folding process, because the folding of newly synthesized proteins is different from the refolding of chemically unfolded or heat-denatured proteins. In this study, we investigated the function of a polysaccharide nanogel to chaperone the folding of GFP synthesized in a cell-free (in vitro) protein synthesis system. The cell-free system consists of a minimal set of transcription/translation factors from Escherichia coli. ${ }^{30-32}$ However, this system lacks factors mediating protein folding, such as molecular chaperones, and it is difficult to obtain relatively hydrophobic proteins that are correctly folded without forming aggregates. Many additives have been tested, and cotranslation with the natural molecular chaperone GroEL/ES has been tested to increase the efficiency of protein production. ${ }^{33,34}$ This study examined the ability of the nanogel to chaperone the folding of GFP expressed in the cell-free system by fluorescence spectroscopy, western blotting and high-performance liquid chromatography (HPLC).

\section{MATERIALS AND METHODS}

\section{Materials}

CHP substituted with 1.2 cholesteryl groups per 100 glucose units of the parent pullulan (molecular weight 100000) was obtained using the previously described method. ${ }^{24}$ All reagents were commercially available with guaranteed purity and were used without further purification. The cell-free protein synthesis kit (E. coli S30 Extract System for circular DNA), which enables protein expression from supercoiled DNA containing natural E. coli promoters (such as lac or tac), was purchased from Promega (Madison, WI, USA). Rabbit anti-GFP antibody (Living Colors A.v. Peptide Antibody) was purchased from BD Biosciences (San Jose, CA, USA). Biotinylated goat antirabbit IgG antibody, biotinylated alkaline phosphatase, streptavidin and alkaline phosphatase colordeveloping buffer were purchased from Bio-Rad (Hercules, CA, USA). The expression plasmids used in this study (pQBI T7) were purchased from Takara Bio (Shiga, Japan).

\section{Preparation of polysaccharide nanogels}

CHP was suspended and swollen in MilliQ water (Millipore, Bedford, MA, USA) or buffer by stirring for $12 \mathrm{~h}$ at $25^{\circ} \mathrm{C}$ to form a turbid suspension. The suspension was then sonicated with a probe-type sonicator (SONIFIER 250, BRANSON Japan, Tokyo, Japan; Tip diameter $2 \mathrm{~mm}$ ) at $40 \mathrm{~W}$ for $10 \mathrm{~min}$ under cooling with ice and filtered through three different types of membrane filters (pore sizes 1.2, 0.45, $0.22 \mu \mathrm{m}$; Super Acrodisc 25, Gelman Sciences) to remove dust or metallic particles shed from the titanium transducer tip. A clear aqueous nanogel suspension was obtained.

\section{Cell-free protein synthesis of GFP}

Cell-free protein synthesis was performed according to the manufacturer's instructions. The $100 \mu \mathrm{l}$ reactions were carried out in a 96-well plate. In brief, $20 \mu \mathrm{l}$ of the E. coli S30-reconstituted reaction mixture without amino acids, $15 \mu \mathrm{l}$ of the S30 extract for circular DNA and $5.0 \mu \mathrm{l}$ of the amino-acid mixture solution were gently mixed in a centrifuge tube and incubated at $37^{\circ} \mathrm{C}$. The solution was transferred to a 96-well plate, which contained $50 \mu \mathrm{l}$ of nanogel solution $\left(8.0 \mathrm{mg} \mathrm{ml}^{-1}\right)$, and the plate was then vortexed gently at $37^{\circ} \mathrm{C}$. Finally, $8 \mu \mathrm{l}$ of $0.5 \mu \mathrm{g} \mu \mathrm{l}^{-1}$ of template DNA (pQBI T7) was added to the solution and the plate was then vortexed gently at $37^{\circ} \mathrm{C}$. The synthesized GFP was analyzed by fluorescence measurement (Wallac Arvo Sx-1420 multilabel counter, Perkin Elmer Life Sciences, Boston, MA, USA), SDS-polyacrylamide gel electrophoresis (SDS-PAGE) and western blotting.

\section{Analysis of cell-free synthesized GFP}

The cell-free synthesized GFP molecules were analyzed by western blotting on an SDS-PAGE gel. A volume of $100 \mu \mathrm{l}$ of the reaction mixture was transferred to a microcentrifuge tube and mixed with $400 \mu$ l of acetone in the centrifuge tube and placed on ice for $15 \mathrm{~min}$. The acetone precipitate was collected by centrifugation at $12000 \times g$ for $5 \mathrm{~min}$. The resulting pellet was dried for $1 \mathrm{~h}$ under a vacuum. Next, $20 \mu \mathrm{l}$ of SDS-PAGE sample buffer was added to the pellet and heated at $100{ }^{\circ} \mathrm{C}$ for $10 \mathrm{~min}$. A small aliquot $(15 \mu \mathrm{l})$ of the sample was loaded onto 5-20\% gradient SDS-PAGE (PAGEL, ATTO, Tokyo, Japan) and electrophoresed (AE-6655, ATTO) for about $75 \mathrm{~min}$ at $20 \mathrm{~mA}$. The separated proteins were transferred onto a polyvinylidene difluoride membrane (AE-6665, ATTO) under a constant current of $144 \mathrm{~mA}$. After transfer, the membrane was blocked for $1 \mathrm{~h}$ at room temperature with $0.5 \%$ non-fat dried milk in Tris-buffered saline containing Tween-20 $(20 \mathrm{~mm}$ Tris- $\mathrm{HCl}, 500 \mathrm{~mm}$ $\mathrm{NaCl}, 0.1 \%$ Tween-20, $\mathrm{pH} 7.5$ ) and then incubated with rabbit anti-GFP IgG (BD Bioscience, San Diego, CA, USA) for $1.5 \mathrm{~h}$ at room temperature, followed by incubation with biotinylated goat antirabbit antibody (Bio-Rad, Richmond, CA, USA) for $1.5 \mathrm{~h}$ at room temperature. Finally, the membrane was incubated with the streptavidin-alkaline phosphatase complex (Bio-Rad) for $1.5 \mathrm{~h}$ at room temperature. The GFP band was visualized after treatment with NBT/ BCIP substrate (Bio-Rad) for $30 \mathrm{~min}$ at room temperature.

\section{HPLC}

HPLC was used to examine the interaction between synthesized GFP and CHP nanogels. The reaction mixture was passed through a $0.22-\mu \mathrm{m}$ filter (Ekicrodisc 3, Gelman Sciences, Ann Arbor, MI, USA). The solution $(100 \mu \mathrm{l})$ was applied to the column (TSK-Gel-G4000SW $\mathrm{XL}_{\mathrm{L}}$ column, Tosoh, Tokyo, Japan) for HPLC and the fractions were collected every $1 \mathrm{ml}$. The HPLC system consisted of a CCPS dual pump (Tosoh), an SD-8022 degasser (Tosoh), a CO-8020 column oven (Tosoh), an RI-8020 R.I. detector (Tosoh), a UV-8020 UV detector (Tosoh) and an FP-2025 fluorescence detector (JASCO, Tokyo, Japan). The elution buffer contained $100 \mathrm{~mm}$ MOPS, $5 \mathrm{~mm} \mathrm{Mg}\left(\mathrm{CH}_{3} \mathrm{COO}\right)_{2} 4 \mathrm{H}_{2} \mathrm{O}$, $5 \mathrm{~mm}$ DTT and $50 \mathrm{~mm}$ MOPS-KOH (pH 7.0). The flow rate was $0.5 \mathrm{ml} \mathrm{min}{ }^{-1}$.

\section{RESULTS AND DISCUSSION}

\section{Cell-free synthesis of GFP in the presence of nanogels}

The effect of CHP nanogels on the cell-free synthesis of GFP was investigated using SDS-PAGE and western blotting (Figure 1). Similar amounts of GFP were expressed when the cell-free synthesis was performed without (lane 3) or with (lane 5) CHP nanogels. Meanwhile, GFP was not expressed in a negative control experiment without the DNA-GFP control vector and with CHP nanogels (lane 4). These results indicate that GFP was effectively produced in the cellfree system, even in the presence of a relatively high concentration of CHP nanogels $\left(4 \mathrm{mg} \mathrm{ml}^{-1}\right)$.

The elemental stages of gene expression are generally considered as (i) transcription, (ii) translation and (iii) post-translation protein folding. ${ }^{35}$ The amount of GFP evaluated by western blotting reflects the net expression of synthesized protein (that is, steps (i) and (ii)). To investigate the effect of CHP nanogels on the downstream processes (that is, step (iii)), the formation of correctly folded, mature GFP was analyzed by fluorescence spectroscopy, as shown in Figure 2. The relative fluorescence intensity of GFP decreased as the CHP nanogel concentration increased, indicating that CHP nanogels inhibit posttranslational folding of the synthesized GFP peptide in the cell-free translation system.

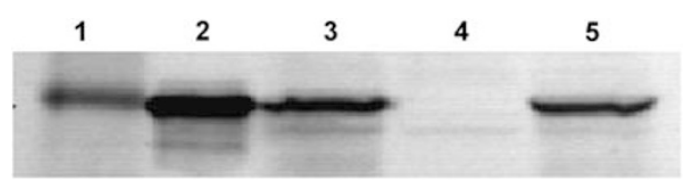

Figure 1 Western blotting analysis of green fluorescent protein (GFP) expressed in a cell-free protein synthesis system with cholesteryl groupbearing pullulan (CHP) nanogels. Lane 1, molecular weight marker (28 kDa); lane 2, GFP: lane 3, GFP synthesized in the cell-free system without CHP nanogels; lane 4, negative control (no DNA template with CHP nanogels); lane 5 , GFP synthesized in a cell-free system with $4.0 \mathrm{mg} \mathrm{ml}^{-1}$ of $\mathrm{CHP}$ nanogels. 
Interaction between nanogels and GFP in the cell-free system CHP nanogels inhibited the folding of newly synthesized GFP in the cell-free system, whereas the upstream transcription and translation processes were not affected. Our previous results indicate that CHP nanogels can selectively trap unfolded proteins or refolding intermediates $^{21-23}$ that expose relatively hydrophobic domains to the aqueous solution. Thus, one hypothesis to explain the inhibition of GFP folding is that the unfolded or partially folded GFP peptides become trapped in the hydrogel matrix of CHP nanogels. Therefore, to clarify the interaction between CHP nanogels and GFP in the

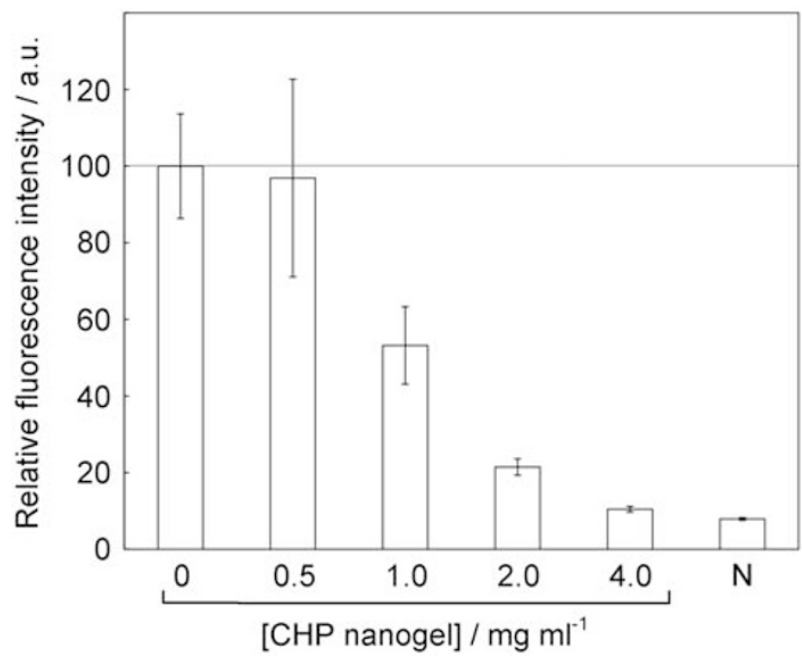

Figure 2 Relative fluorescence intensity of green fluorescent protein (GFP) expressed by cell-free protein synthesis with various concentrations of cholesteryl group-bearing pullulan (CHP) nanogels at $37^{\circ} \mathrm{C}$. a.u., arbitrary units; $\mathrm{N}$, negative control (no DNA template with $\mathrm{CHP}$ nanogels). GFP: excitation $=395 \mathrm{~nm}$, emission $=509 \mathrm{~nm}$. cell-free synthesis system, the solution collected after the expression of GFP in the presence of CHP nanogels was analyzed by HPLC.

Figure 3a shows the chromatogram for CHP nanogels and GFP detected by the refractive index and fluorescence, respectively. The CHP nanogels were eluted at $\sim 18 \mathrm{~min}$, whereas GFP was eluted at $\sim 28 \mathrm{~min}$. The solution collected after GFP expression in the presence of CHP nanogels was applied to the column under this condition. Thereafter, fractions were collected every $2 \mathrm{~min}$ and analyzed by western blotting (Figure $3 \mathrm{~b}$ ). The fraction collected between 14 and 22 min (fractions 7-11), corresponding to the elution time of CHP nanogels, showed relatively strong bands for GFP. In contrast, the fraction collected between 25 and $38 \mathrm{~min}$ (fractions 13-18), corresponding to the elution of native GFP, showed no GFP band. This observation means that the synthesized GFP complexed with CHP nanogels in the unfolded or partially folded state, as the complexed GFP with CHP nanogels showed no fluorescence. The complexation behavior is similar to that of the molecular chaperone (GroEL/ES), which can selectively trap denatured proteins more effectively than native proteins.

\section{Cyclodextrin-induced release of GFP from nanogels and subsequent folding}

Protein release and refolding, which are induced by ATP in natural molecular chaperone systems, were induced in the nanogel system using cyclodextrin. The main driving force of the formation of nanogels is the association of CHP hydrophobic cholesteryl groups in water. Cyclodextrins can solubilize hydrophobic compounds in water by incorporating the compounds into their hydrophobic cavities. CHP nanogels dissociate on complexation with $\beta$-cyclodextrin $(\beta-C D)$ to yield a dissociated CHP-CD complex, ${ }^{36,37}$ because the cholesteryl group is a suitable guest for $\beta$-CD. ${ }^{38}$ Thus, the dissociation of the CHP nanogel-protein complex allows for the release and renaturation of proteins. In a previous study, we showed that the acid-denatured GFP that complexed with CHP nanogels was released and refolded by the addition of $\beta-\mathrm{CD} .^{26}$ On the basis of these results,

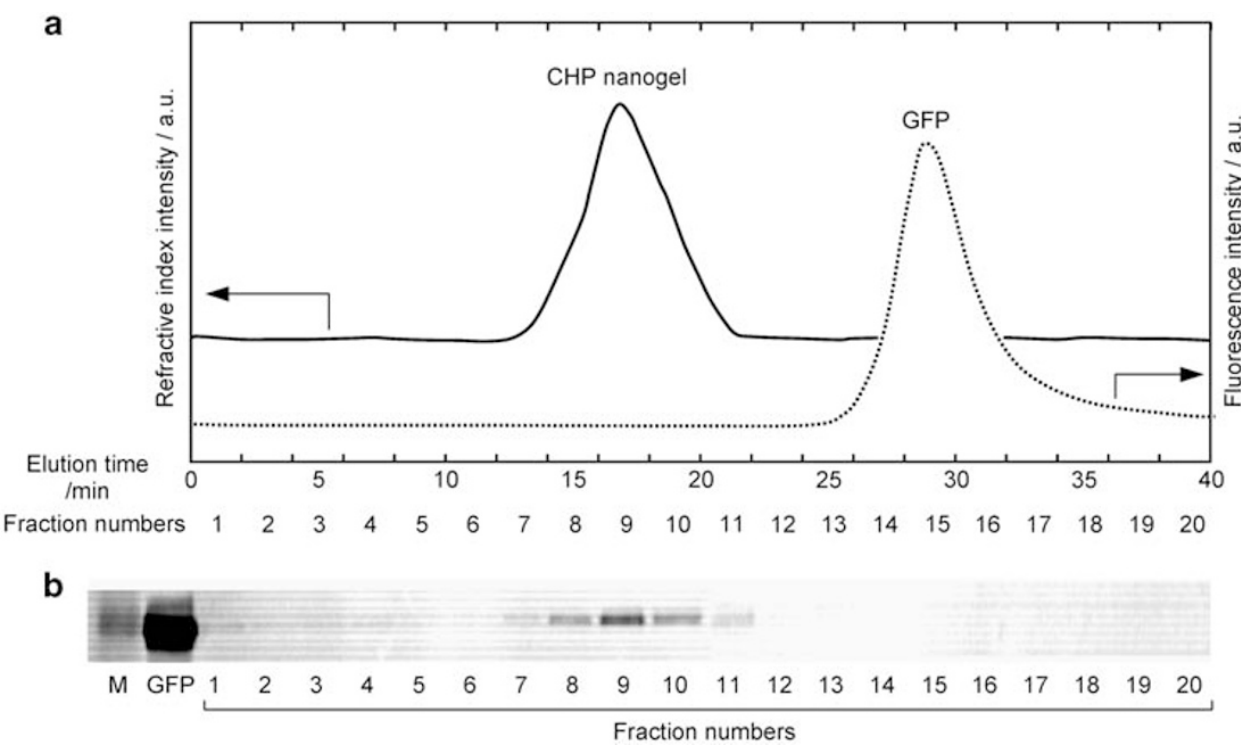

Figure 3 (a) Elution profiles of green fluorescent protein (GFP) expressed in a cell-free synthesis system in the presence of cholesteryl group-bearing pullulan (CHP) nanogels (solid line) and GFP (dashed line) detected by refractive index intensity and fluorescence intensity (excitation=395 nm, emission=509 $\mathrm{nm}$ ), respectively. a.u., arbitrary units. (b) Western blotting analysis of the eluted sample of GFP expressed in the cell-free system in the presence of CHP nanogels (elution fractions 1-20). Sample M, molecular weight marker (28 kDa). 


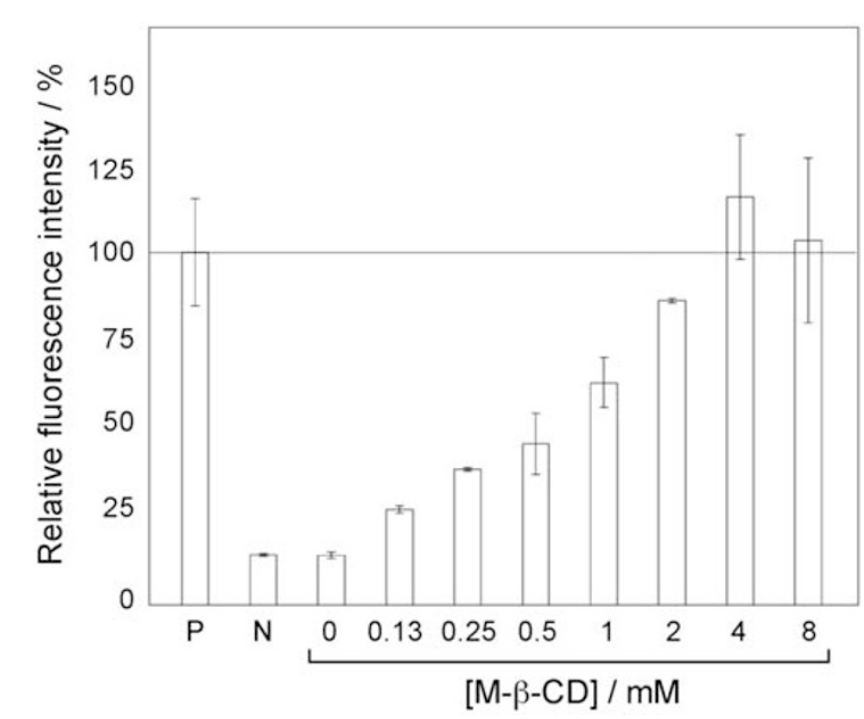

Figure 4 Relative fluorescence intensity of green fluorescent protein (GFP) expressed in the presence of nanogels after the addition of various concentrations of methyl- $\beta$-cyclodextrins (M- $\beta$-CD). GFP was synthesized in the presence of $4.0 \mathrm{mg} \mathrm{ml}^{-1}$ of cholesteryl group-bearing pullulan (CHP) nanogels at $37^{\circ} \mathrm{C}$ for $6.5 \mathrm{~h}$. Thereafter, various concentrations of $M-\beta-C D$ were added to the solutions and incubated for $12 \mathrm{~h}$ at $37^{\circ} \mathrm{C}$. Sample P, positive control (no CHP nanogels or M- $\beta-C D$ ). Sample N, negative control (no DNA template with CHP nanogels). GFP: excitation $=395 \mathrm{~nm}$, emission $=509 \mathrm{~nm}$.

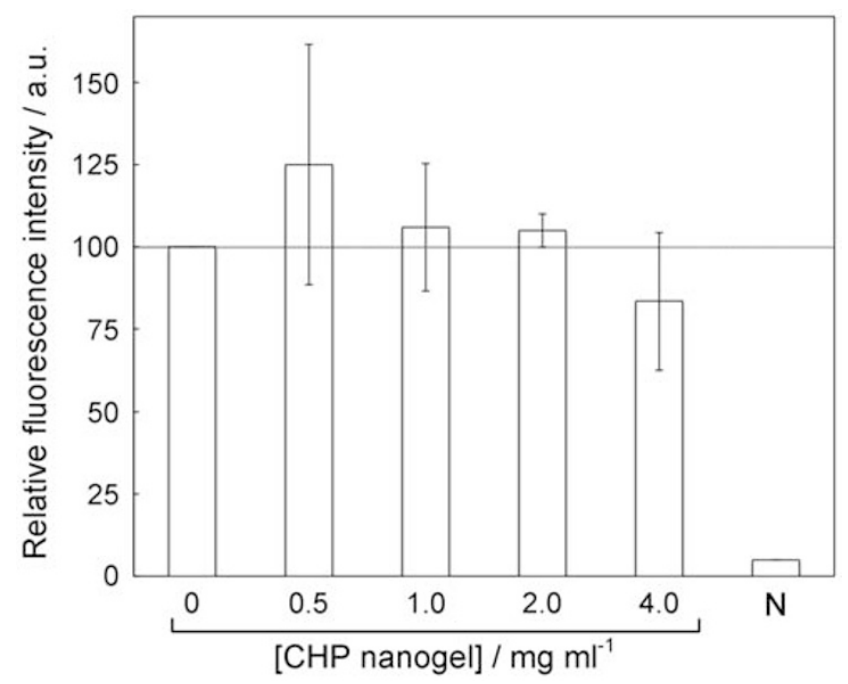

Figure 5 Relative fluorescence intensity of green fluorescent protein (GFP) expressed in the cell-free protein synthesis system in the presence of various concentrations of cholesteryl group-bearing pullulan (CHP) nanogels. GFP was synthesized in the presence of $\mathrm{CHP}$ nanogels at $37^{\circ} \mathrm{C}$ for $4 \mathrm{~h}$. After $4 \mathrm{~h}$, $14.5 \mathrm{~mm}$ of methyl- $\beta$-cyclodextrins (M- $\beta-\mathrm{CD})$ was added to the solutions and incubated for $12 \mathrm{~h}$ at $37^{\circ} \mathrm{C}$. a.u., arbitrary units; N, negative control (no DNA template with CHP nanogels). GFP: excitation $=395 \mathrm{~nm}$, emission $=$ $509 \mathrm{~nm}$.

we examined the release of GFP from the CHP nanogel in the presence of $\beta$-CD using the current cell-free system.

Figure 4 shows the fluorescence intensity of GFP released from CHP nanogels by adding various concentrations of methyl- $\beta$-cyclodextrin $(\mathrm{M}-\beta-\mathrm{CD})$ after expression in the cell-free system. The fluorescence

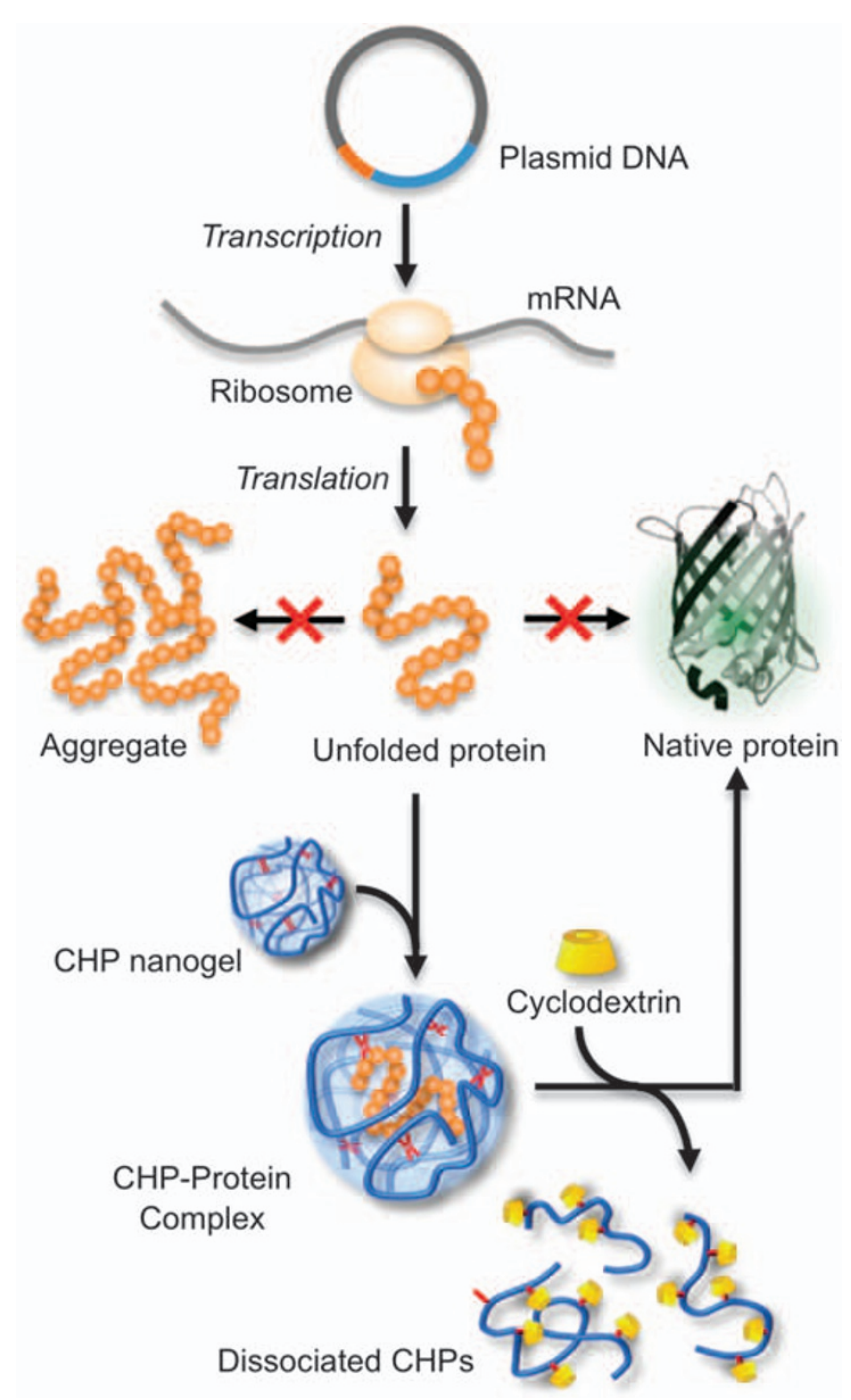

Figure 6 Schematic representation of the folding of green fluorescent protein (GFP) mediated by cholesteryl group-bearing pullulan (CHP) nanogels. The CHP nanogel formed a complex with unfolded protein, and the protein was released in its native form by the addition of methyl- $\beta$ cyclodextrins (M- $\beta-C D)$.

intensity corresponds to the ratio of correctly folded GFP after translation. GFP was synthesized in the presence of $4.0 \mathrm{mg} \mathrm{ml}^{-1}$ $\mathrm{CHP}$ nanogels at $37^{\circ} \mathrm{C}$ for $6.5 \mathrm{~h}$. Thereafter, various concentrations of $\mathrm{M}-\beta-\mathrm{CD}$ were added to the solutions and incubated for $12 \mathrm{~h}$ at $37^{\circ} \mathrm{C}$. The relative fluorescence intensity increased with increasing $\mathrm{M}-\beta-\mathrm{CD}$ concentration. In the presence of $4.0 \mathrm{~mm} \mathrm{M}-\beta-\mathrm{CD}$, which is sufficient to dissociate CHP $\left(4.0 \mathrm{mg} \mathrm{ml}^{-1}\right)$, the relative fluorescence intensity was recovered to nearly $100 \%$. Figure 5 shows the relative fluorescence intensity as an indicator of the folding efficiency of GFP as a function of CHP nanogel concentration. In the presence of a low concentration of CHP nanogels $\left(0.036-0.063 \mathrm{mg} \mathrm{ml}^{-1}\right)$, the relative fluorescence intensity of GFP reached almost $100 \%$. Moderate concentrations of CHP nanogels $\left(0.125-2.0 \mathrm{mg} \mathrm{m}^{-1}\right)$ elicited the most efficient protein folding, whereas a relatively high $\left(4.0 \mathrm{mg} \mathrm{ml}^{-1}\right)$ concentration decreased folding efficiency. These results indicate that CHP nanogels formed a complex with unfolded or partially folded proteins and that the protein was released in its native form by the addition of $\mathrm{M}-\beta-\mathrm{CD}$ (Figure 6), although the fact that 


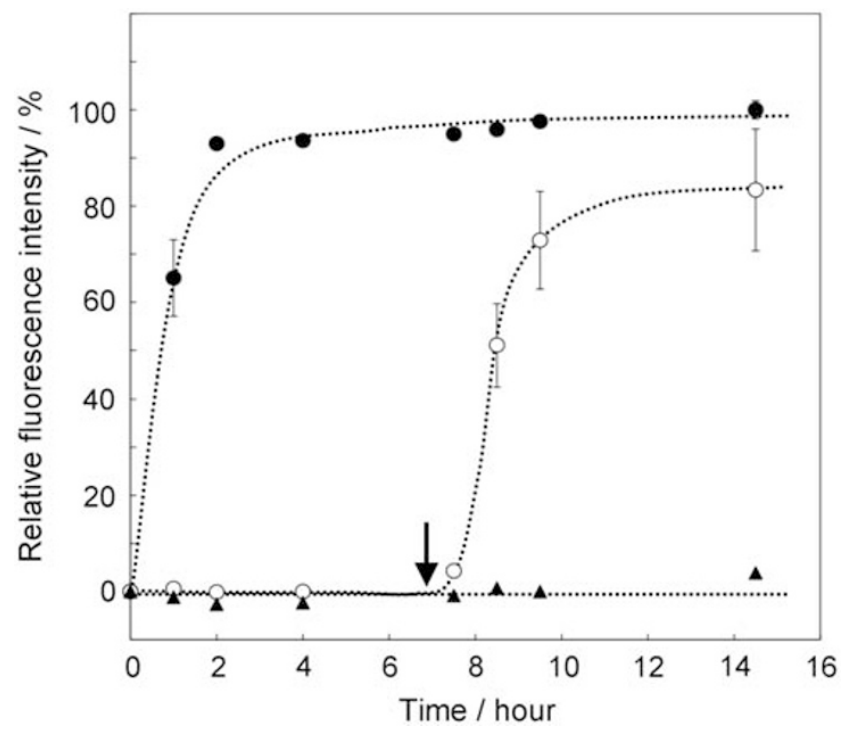

Figure 7 Time course of relative fluorescence intensity of green fluorescent protein (GFP) expressed in the presence (closed triangles and open circles) or absence (closed circles) of cholesteryl group-bearing pullulan (CHP) nanogels $\left(4.0 \mathrm{mg} \mathrm{ml}^{-1}\right)$. After $6.5 \mathrm{~h}$, methyl- $\beta$-cyclodextrins (M- $\beta$-CD) $(14.5 \mathrm{~mm})$ was added to the solutions containing expressed proteins and CHP nanogels (open circle, arrow).

moderate concentrations of CHP nanogels were the most effective for folding cannot simply be explained by the complexation between the CHP nanogel and GFP.

The refolding kinetics of expressed GFP after the addition of M- $\beta$ $\mathrm{CD}$ was examined by monitoring the relative fluorescence intensity of GFP, as shown in Figure 7 . When M- $\beta-C D$ was added to the expressed solution containing CHP nanogels, the relative fluorescence intensity increased gradually, but refolding did not take place in the absence of $\mathrm{M}-\beta$-CD. The folding curves showed a good fit with a single exponential function. The CHP-M- $\beta$-CD-assisted folding curve of GFP seems to be comparable to the spontaneous folding curve without CHP or M- $\beta$-CD. The half-life values $\left(t_{1 / 2}\right)$ for the total reaction determined from these curves were 39 and $42 \mathrm{~min}$ for $\mathrm{CHP}-$ $\mathrm{M}-\beta$-CD-assisted folding and spontaneous folding, respectively. Chromophore formation of GFP, which occurs with complete folding, requires three discrete physical processes, that is, the formation of three-dimensional metastable structures, chromophore cyclization and oxidation into a fluorescent molecule. ${ }^{39-41}$ The formation of three-dimensional metastable structures before chromophore modification occurred at $t_{1 / 2}=\sim 10 \mathrm{~min}$. Thereafter, an intermediate step including cyclization of the tripeptide chromophore motif occurred at $\mathrm{t}_{1 / 2}=\sim 3 \mathrm{~min}$. Finally, the relatively slow chromophore formation process involving oxidation of the cyclic chromophore took place at $\mathrm{t}_{1 / 2}=\sim 80 \mathrm{~min}$. These kinetic parameters indicate that the oxidation step is the rate-determining step of protein folding. In addition, $\mathrm{M}-\beta$ $\mathrm{CD}$-mediated dissociation from CHP was completed within several minutes. Considering these results, the similarity of the folding kinetics in the CHP-mediated and spontaneous systems indicates that CHP nanogels form complexes with GFP in a relatively early stage of the folding process, at least before chromophore cyclization.

In summary, this work demonstrated the ability of a polysaccharide nanogel to function as a chaperone for the folding of newly synthesized GFP in a cell-free system, although the folding was not accelerated in this system. GFP was expressed and folded in its active form, even in the presence of transcription/translation factors, which could affect the function of the nanogel. The mechanism of folding with nanogels seems to be similar to that previously documented ${ }^{20}$ for artificial chaperone-assisted refolding from chemically and thermally denatured proteins. Although this technology is still under development, we believe that the cell-free protein synthesis system using nanogels and cyclodextrins will become a powerful tool that enables high expression levels of unstable proteins that easily form aggregates.

\section{ACKNOWLEDGEMENTS}

This work was supported by Grants-in-Aid for Scientific Research from the Japanese government (nos. 20240047 and 18GS0421).

1 Clark, D. B. B. Refolding of recombinant proteins. Curr. Opin. Biotechnol. 9, 157-163 (1998).

2 Baneyx, F. Recombinant protein expression in Escherichia Coli. Curr. Opin. Biotechnol. 10, 411-421 (1999).

3 Horwich, A. Protein aggregation in disease: a role for folding intermediates forming specific multimeric interactions. J. Clin. Invest. 110, 1221-1232 (2002).

4 Prusiner, S. B. \& Hsiao, K. K. Human prion diseases. Annals Neurol. 35, 385-395 (1994).

5 Carrell, R. W. \& Lomas, D. A. Conformational disease. Lancet 350, 134-138 (1997).

6 Markossian, K. A. \& Kurganov, B. I. Protein folding, misfolding, and aggregation. Formation of inclusion bodies and aggresomes. Biochemistry (Mosc.) 69, 971-984 (2004).

7 Lovestone, S. \& McLoughlin, D. M. Protein aggregates and dementia: is there a common toxicity? J. Neurol. Neurosurg. Psychiatry 72, 152-161 (2007).

8 Ben-zvi, A. P. \& Goloubinoff, P. Mechanisms of disaggregation and refolding of stable protein aggregates by molecular chaperones. J. Struct. Biol. 135, 84-93 (2001).

9 Ranson, N. A., White, H. E. \& Saibil, H. R. Chaperonins. Biochem. J. 333, 233-242 (1998).

10 Bukau, B. \& Horwich, A. L. The Hsp70 and Hsp60 chaperone machines. Cell 92, 351-366 (1998).

11 Ellis, R. J. Molecular chaperones: inside and outside the anfinsen cage. Curr. Biol. 11, R1038-R1040 (2001).

12 Hartl, F. U. \& Hayer-Hartl, M. Molecular chaperones in the cytosol: from nascent chain to folded protein. Science 295, 1852-1858 (2002)

13 Rozema, D. \& Gellman, S. H. Artificial chaperones: protein refolding via sequential use of detergent and cyclodextrin. J. Am. Chem. Soc. 117, 2373-2374 (1995).

14 Machida, S., Ogawa, S., Xiaohua, S., Takaha, T., Fujii, K. \& Hayashi, K. Cycloamylose as an efficient artificial chaperone for protein refolding. FEBS Lett. 486, 131-135 (2000)

15 Yoshimoto, N., Hashimoto, T., Felix, M. M., Umakoshi, H. \& Kuboi, R. Artificial chaperone-assisted refolding of bovine carbonic anhydrase using molecular assemblies of stimuli-responsive polymers. Biomacromolecules 4, 1530-1538 (2003).

16 Lanckriet, H. \& Middelberg, A. P. J. Operational regimes for a simplified one-step artificial chaperone refolding method. Biotechnol. Prog. 20, 1861-1867 (2004).

17 Lu, D., Zhang, K. \& Liu, Z. Protein refolding assisted by an artificial chaperone using temperature stimuli responsive polymer as the stripper. Biochem. Eng. J. 25, 141-149 (2005).

18 Yazdanparast, R. \& Khodarahmi, R. Evaluation of artificial chaperoning behavior of an insoluble cyclodextrin-rich copolymer: solid-phase assisted refolding of carbonic anhydrase. Int. J. Biol. Macromol. 40, 319-326 (2007).

19 Jungbauer, A. \& Kaar, W. Current status of technical protein refolding. J. Biotech. $\mathbf{1 2 8}$ 587-596 (2007).

20 Sasaki, Y. \& Akiyoshi, K. Development of an artificial chaperone system based on cyclodextrin. Curr. Pharm. Biotechnol. 11, 300-305 (2010).

21 Akiyoshi, K., Sasaki, Y. \& Sunamoto, J. Molecular chaperone-like activity of hydrogel nanoparticles of hydrophobized pullulan: thermal stabilization with refolding of carbonic anhydrase B. Bioconjugate Chem. 10, 321-324 (1999).

22 Nomura, Y., Ikeda, M., Yamaguchi, N., Aoyama, Y. \& Akiyoshi, K. Protein refolding assisted by self-assembled nanogels as novel artificial molecular chaperone. FEBS Lett 553, 271-276 (2003).

23 Nomura, Y., Sasaki, Y., Takagi, M., Narita, T., Aoyama, Y. \& Akiyoshi, K. Thermoresponsive controlled association of protein with a dynamic nanogel of hydrophobized polysaccharide and cyclodextrin: heat shock protein-like activity of artificial molecular chaperone. Biomacromolecules 6, 447-452 (2005).

24 Akiyoshi, K., Deguchi, S., Moriguchi, N., Yamaguchi, S. \& Sunamoto, J. Self-aggregates of hydrophobized polysaccharides in water. formation and characteristics of nanoparticles. Macromolecules 26, 3062-3068 (1993).

25 Akiyoshi, K., Deguchi, S., Tajima, H., Nishikawa, T. \& Sunamoto, J. Microscopic structure and thermoresponsiveness of a hydrogel nanoparticle by self-assembly of a hydrophobized polysaccharide. Macromolecules 30, 857-861 (1997).

26 Akiyoshi, K. \& Sunamoto, J. Supramolecular assembly of hydrophobized polysaccharides. Supramol. Sci. 3, 157-163 (1996) 
27 Asayama, W., Sawada, S., Taguchi, H. \& Akiyoshi, K. Comparison of refolding activities between nanogel artificial chaperone and GroEL systems. Int. J. Biol. Macromol. 42, 241-246 (2008).

28 Ikeda, K., Okada, T., Sawada, S., Akiyoshi, K. \& Matsuzaki, K. Inhibition of the formation of amyloid $\beta$-protein fibrils using biocompatible nanogels as artificial chaperones. FEBS Lett. 580, 6587-6595 (2006).

29 Boridy, S., Takahashi, H., Akiyoshi, K. \& Maysinger, D. The binding of pullulan modified cholesteryl nanogels to Abeta oligomers and their suppression of cytotoxicity. Biomaterials 30, 5583-5591 (2009).

30 Shimizu, Y., Kuruma, Y., Ying, B- W., Umekage, S. \& Ueda, T. Cell-free translation for protein engineering. FEBS J. 273, 4133-4140 (2006).

31 Shimizu, Y., Kanamori, T. \& Ueda, T. Protein synthesis by PURE translation systems. Methods 36, 299-304 (2005).

32 Shimizu, Y., Inoue, A., Tomari, Y., Suzuki, T., Yokogawa, T., Nishikawa, K. \& Ueda, T. Cell-free translation reconstituted with purified components. Nat. Biotechnol. 19, 751-755 (2001).

33 Ying, B- W., Taguchi, H., Ueda, H. \& Ueda, T. Chaperone-assisted folding of a singlechain antibody in a Reconstituted Translation System. Biochem. Biophys. Res. Commun. 320, 1359-1364 (2004).
34 Ying, B- W., Taguchi, H., Kondo, M. \& Ueda, T. Co-translational involvement of the chaperonin GroEL in the folding of newly translated polypeptides. J. Biol. Chem. 280, 12035-12040 (2005).

35 Bui, H. T., Umakoshi, H., Suga, K., Nishida, M., Shimanouchi, T. \& Kuboi, R. Negatively charged liposome as a potent inhibitor of post-translation during in vitro synthesis of green fluorescent protein. Biochem. Eng. J. 46, 154-160 (2009).

36 Akiyoshi, K., Sasaki, Y., Kuroda, K. \& Sumanoto, J. Controlled association of hydrophobized polysaccharide by cyclodextrin. Chem. Lett. 27, 93-94 (1998).

37 Inomoto, N., Osaka, N., Suzuki, T., Hasegawa, U., Ozawa, Y., Endo, H., Akiyoshi, K. \& Shibayama, M. Interaction of nanogel with cyclodextrin or protein: study by dynamic light scattering and small-angle neutron scattering. Polymer 50, 541-546 (2009).

38 Villalonga, R., Cao, R. \& Fragoso, A. Supramolecular chemistry of cyclodextrins in enzyme technology. Chem. Rev. 107, 3088-3116 (2007).

39 Heim, R., Cubitt, A. B. \& Tsien, R. Y. Improved green fluorescence. Nature 373, 663-664 (1995).

40 Cubitt, A. B., Heim, R., Adams, S. R., Boyd, A. E., Gross, L. A. \& Tsien, R. Y. Understanding, improving and using green fluorescent proteins. Trends Biochem. Sci. 20, 448-455 (1995).

41 Reid, B. G. \& Flynn, G. C. Chromophore formation in green fluorescent protein. Biochemistry 36, 6786-6791 (1997). 